\title{
Composição florística e fitossociológica de um remanescente de floresta ombrófila mista
}

\author{
Amauri Bambolim¹, Júlio César Wojciechowski ${ }^{1}$ \\ ${ }^{1}$ Universidade do Estado de Mato Grosso - UNEMAT, Campus Universitário de Alta Floresta, Alta Floresta, Mato Grosso, Brasil. \\ E-mail: amauribambolim@outlook.com,cw.julio@gmail.com
}

Recebido: 04/07/2016; Aceito: 05/12/2016.

\section{RESUMO}

O estudo da composição florística e fitossociológica das florestas naturais são essenciais para a compreensão do funcionamento das comunidades vegetais. O presente estudo teve como objetivo conhecer, analisar e descrever a composição florística e a estrutura do componente arbóreo de um remanescente de Floresta Ombrófila Mista, na Floresta Nacional do município de São Francisco de Paula no estado do Rio Grande do Sul. Foram instaladas 100 parcelas de $10 \times 10$ demarcadas em um hectare no interior da floresta onde foram medidos e identificados todos os indivíduos com $\mathrm{CAP} \geq 30 \mathrm{~cm}$. A densidade total foi de 835 indivíduos/ha, pertencentes a 42 espécies, 29 gêneros e 17 famílias botânicas. As famílias Myrtaceae, Lauraceae e Euphorbiaceae apresentaram o maior número de espécies. A espécie Blepharocalyx salicifolius, apresentou o maior índice de valor de importância (IVI) e o maior índice de valor de cobertura (IVC). Observou-se alto valor do índice de diversidade de Shannon (H' 3,18 nats/ind) e Equabilidade de Pielou (J'0,84). As classes de altura dominante dos indivíduos foram entre 11 e $17 \mathrm{~m}$ e as classes de diâmetro foram entre 9 e $29 \mathrm{~cm}$. Constatou-se que a dominância de indivíduos de menor diâmetro garantirá a presença dessas espécies a médio prazo.

Palavras-chave: fitossociologia; estrutura florestal; floresta ombrófila mista.

\section{Floristic and phytosociological composition of a remnant of mixed ombrophilous forest}

\begin{abstract}
The floristic and phytosociological composition study of natural forests is essential for understanding the functioning of plant communities. The present study aimed to meet, analyze and describe the floristic composition and structure of the tree component of a remaining mixed Ombrophilous forest, from the National Forest at São Francisco de Paula municipality, in the State of Rio Grande do Sul, Brazil. It was installed 10010 x 10 plots demarcated in one hectare within the forest where they were measured and identified all individuals with $\mathrm{DBH} \geq$ $30 \mathrm{~cm}$. The total density was 835 individuals/ha, belonging to 42 species, 29 genera and 17 botanical families. The Myrtaceae family, Lauraceae and Euphorbiaceae showed the largest number of species. The species Blepharocalyx salicifolius, presented the highest importance value index (IVI) and the highest value (IVC). It was observed high value of Shannon diversity index (H 3.18 nats/ind) and Pielou Evenness (J ' 0.84). Dominant height classes of individuals were between 11 and $17 \mathrm{~m}$ and the diameter classes were between 9 and $29 \mathrm{~cm}$. It was noted that the smaller diameter individuals' dominance will ensure the presence of these species in the medium term.
\end{abstract}

Key words: phytosociology; forest structure; mixed ombrophilous forest. 


\section{Introdução}

A Floresta ombrófila mista, também conhecida como floresta de araucária cobria inicialmente 175 mil $\mathrm{km}^{2}$ na região sul do Brasil, atualmente devido ao forte impacto antrópico essa área foi reduzida para $20 \mathrm{mil}$ $\mathrm{km}^{2}$ (LEITE; KLEIN, 1990). Uma das estratégias de conservação mais eficientes da biodiversidade é a criação de unidades de conservação, pois estas contribuem para a proteção das comunidades vegetais que ocorrem nas regiões e consequentemente mantem os processos ecológicos, incluindo aqueles de importância para o ser humano, como a conservação do solo, a ciclagem de nutrientes e a proteção dos cursos d'água (DOBROVOLSKI et al., 2006).

Devido aos altos níveis de perturbação antrópica, a conservação da biodiversidade tem se tornado um desafio. Os estudos sobre a composição florística e a estrutura fitossociológica das formações florestais são de grande importância para recomposição de ecossistemas degradados, pois oferecem base para a compreensão da estrutura e da dinâmica destas formações; parâmetros essenciais para o manejo e regeneração das diferentes comunidades vegetais (CHAVES et al., 2013).

Para se conhecer o comportamento da vegetação de uma determinada área é necessário identificar as espécies presentes no local e fazer uma análise da estrutura horizontal e vertical da floresta com o objetivo de verificar seu desenvolvimento. A estrutura horizontal permite verificar a densidade, dominância, frequência e importância das espécies na floresta e a estrutura vertical mostra o estágio de desenvolvimento desta floresta, com base na distribuição das espécies nos diferentes estratos (LONGHI et al., 2000).
Nesse contexto, a fitossociologia tem se tornado um importante meio de se conhecer as comunidades vegetais de maneira mais ampla, além de servir para explicar os fenômenos que se relacionam com a vida das plantas dentro das unidades ecológicas (CHAVES et al., 2013).

O estudo da composição florística e da estrutura fitossociológica de uma comunidade vegetal, pode se tornar uma forte base teórica para elaboração de projetos de conservação de recursos genéticos de áreas similares e recuperação de áreas degradados, contribuindo para seu manejo (VILELA et al., 1993).

Segundo Martins (1989), a fitossociologia pode ser definida como sendo o estudo das relações entre espécies vegetais dentro da comunidade e refere-se ao estudo quantitativo do desenvolvimento da floresta e a dinâmica da comunidade tornando se distinta de um estudo de composição florística. O presente trabalho teve como objetivo determinar a composição florística e a estrutura fitossociológica do componente arbóreo de uma área de floresta ombrófila mista, na Floresta Nacional de São Francisco de Paula.

\section{Material e Métodos}

A Floresta Nacional de São Francisco de Paula (Flona-SFP) está localizada na região nordeste do Rio Grande do Sul (Figura. 1), sob as coordenadas $29^{\circ} 23^{\prime}$ e $29^{\circ} 27^{\prime} \mathrm{S} 50^{\circ} 23^{\prime}$ e $50^{\circ} 25^{\prime} \mathrm{W}$ e possui uma área total de 1.606,69 ha. Constitui-se em um dos ambientes de transição entre a Floresta ombrófila densa (Mata Atlântica) e a Floresta ombrófila mista.

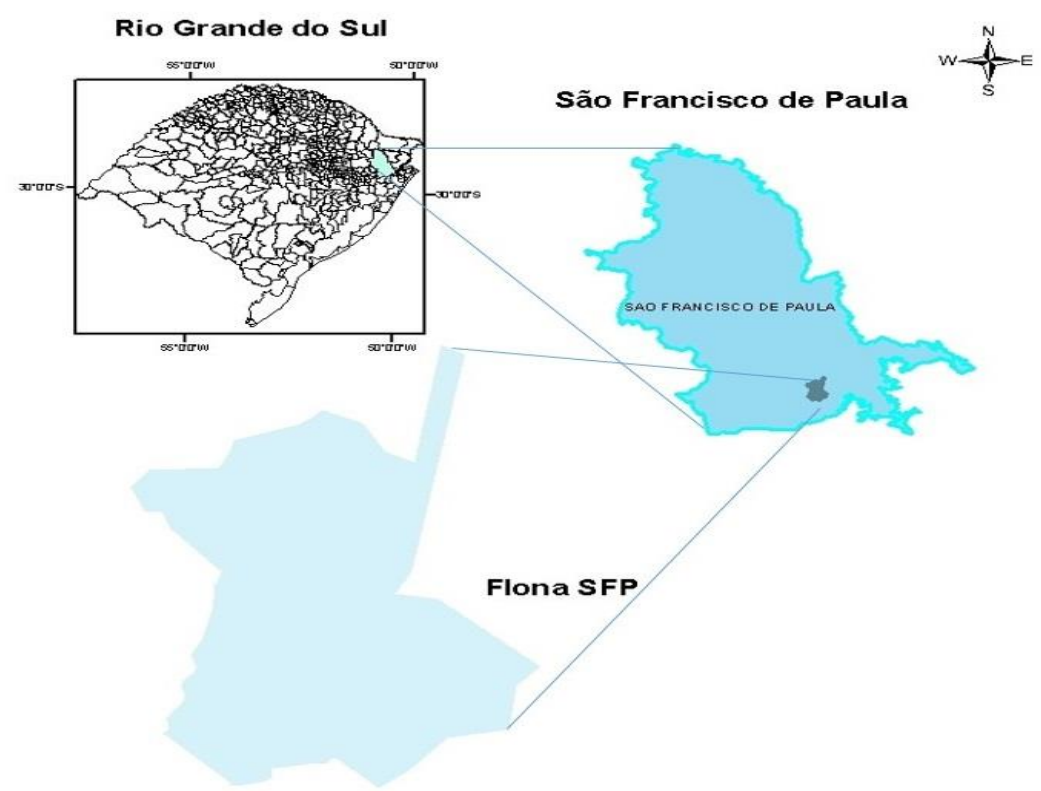

Figura 1. Localização da Floresta Nacional de São Francisco de Paula, Rio Grande do Sul, Brasil. 
O clima da região, de acordo com a classificação de Köppen, é do tipo "Cfb", mesotérmico médio e altura próxima a $1.000 \mathrm{~m}$ acima do nível do mar. O levantamento florístico e fitossociológico foi realizado adotando-se o método de parcelas contíguas, seguindo a metodologia de Muller-Dombois e Ellemberg (1974). Foram estabelecidas 100 unidades amostrais de 10 x 10 $\mathrm{m}\left(100 \mathrm{~m}^{2}\right)$ totalizando uma área de $1 \mathrm{ha}$, onde foram registradas, identificadas e mensuradas todas as árvores com circunferência à altura do peito $(\mathrm{CAP}) \geq 30 \mathrm{~cm}$.

Para determinar a estrutura horizontal da comunidade, foram tomados os seguintes parâmetros: densidade, dominância e frequência (tanto relativa como absoluta), valor de cobertura, (IVC) porcentagem de cobertura, valor de importância, (IVI), porcentagem de por meio do comportamento das espécies que compõem a comunidade estudada, segundo a variável posição sociológica, considerando-se três estratos: superior, médio e inferior, avaliados visualmente.

Para o cálculo da diversidade foi utilizado o índice de diversidade de Shannon (H'). Quanto maior o valor de H', maior a diversidade florística da população em estudo. Também foi utilizado o índice de Pielou (J) que determina o padrão de distribuição dos indivíduos variando entre 0 e 1 , onde 1 representa a máxima diversidade dentro da comunidade. O cálculo dos dados e a representação gráfica foi realizada com o software Microsoft Excel 2013 e R Core Team (2016).

\section{Resultados e Discussão}

A família de maior riqueza florística foi a Myrtaceae com 14 espécies, seguida das famílias Lauraceae com 5, Euphorbiacea e Salicaceae com 4 espécies cada uma (Figura 2). Estas famílias juntas foram responsáveis por 64,28\% das espécies catalogadas. A predominância da família Myrtaceae também foram constatadas por Silva et al. (2011) e Kanieski et al. (2010) em estudos realizados na Flona de São Francisco de Paula, confirmando a importância desta família nas florestas ombrófila mista.

As espécies mais abundantes na área foram Sebastiania commersoniana (108), Blepharocalyx salicifolius (85), Ilex brevicuspis (73), Sapium glandulatum (63) Araucaria angustifólia (44) e Casearia decandra (44) (Figura 2), sendo estas espécies responsáveis por $49.95 \%$ do total das espécies amostradas. Estes resultados não estão de acordo com os trabalhos de Araújo et al. (2010) e Gomes et al. (2008), que verificaram a Araucaria angustifólia, como sendo a espécie predominante em florestas ombrófila mista, porém Gomes et al. (2008), destacaram a presença das espécies Sebastiania commersoniana, Blepharocalyx salicifolius, Ilex brevicuspis dentre as que apresentaram grande número de indivíduos.

A predominância da família Myrtaceae também foi constatada por Silva et al. (2011) e Kanieski et al. (2010) em estudos realizados na Flona de São Francisco de Paula, confirmando a importância desta família nas florestas ombrófila mista.

As espécies mais abundantes na área foram Sebastiania commersoniana (108), Blepharocalyx salicifolius (85), Ilex brevicuspis (73), Sapium glandulatum (63) Araucaria angustifólia (44) e Casearia decandra (44) (Figura 3), sendo estas espécies responsáveis por $49.95 \%$ do total das espécies amostradas.

Com relação à distribuição vertical dos indivíduos dentro da área experimental, foi observado que $53 \%$ de seus indivíduos (448) estão agrupados em uma classe de altura variando entre 11 e $17 \mathrm{~m}$ (Figura 4). A maior altura foi de $31,89 \mathrm{~m}$ para Ilex brevicuspis (Aquifoliaceae) e a menor altura dentre as classes avaliadas foi de 2,30 $\mathrm{m}$ para um indivíduo da espécie Myrcia oligantha (Myrtaceae).

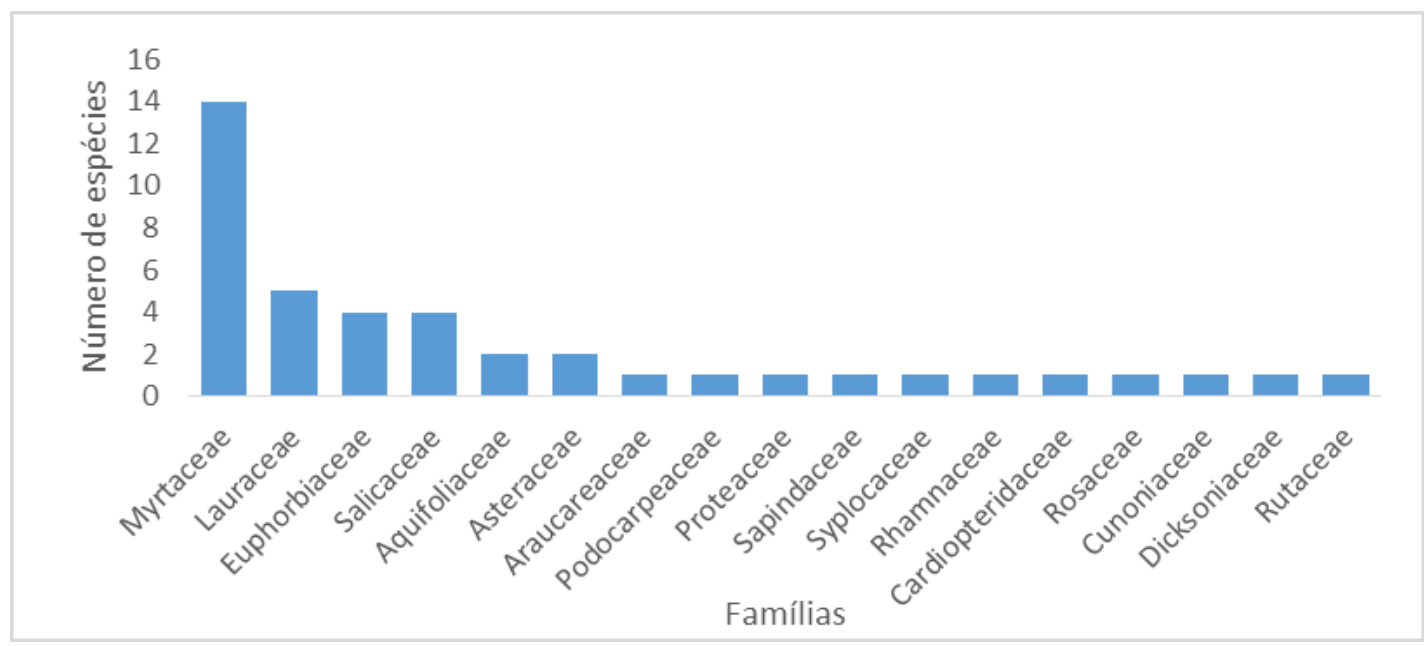

Figura 2. Números de espécies por família inventariados na Flona-SFP 


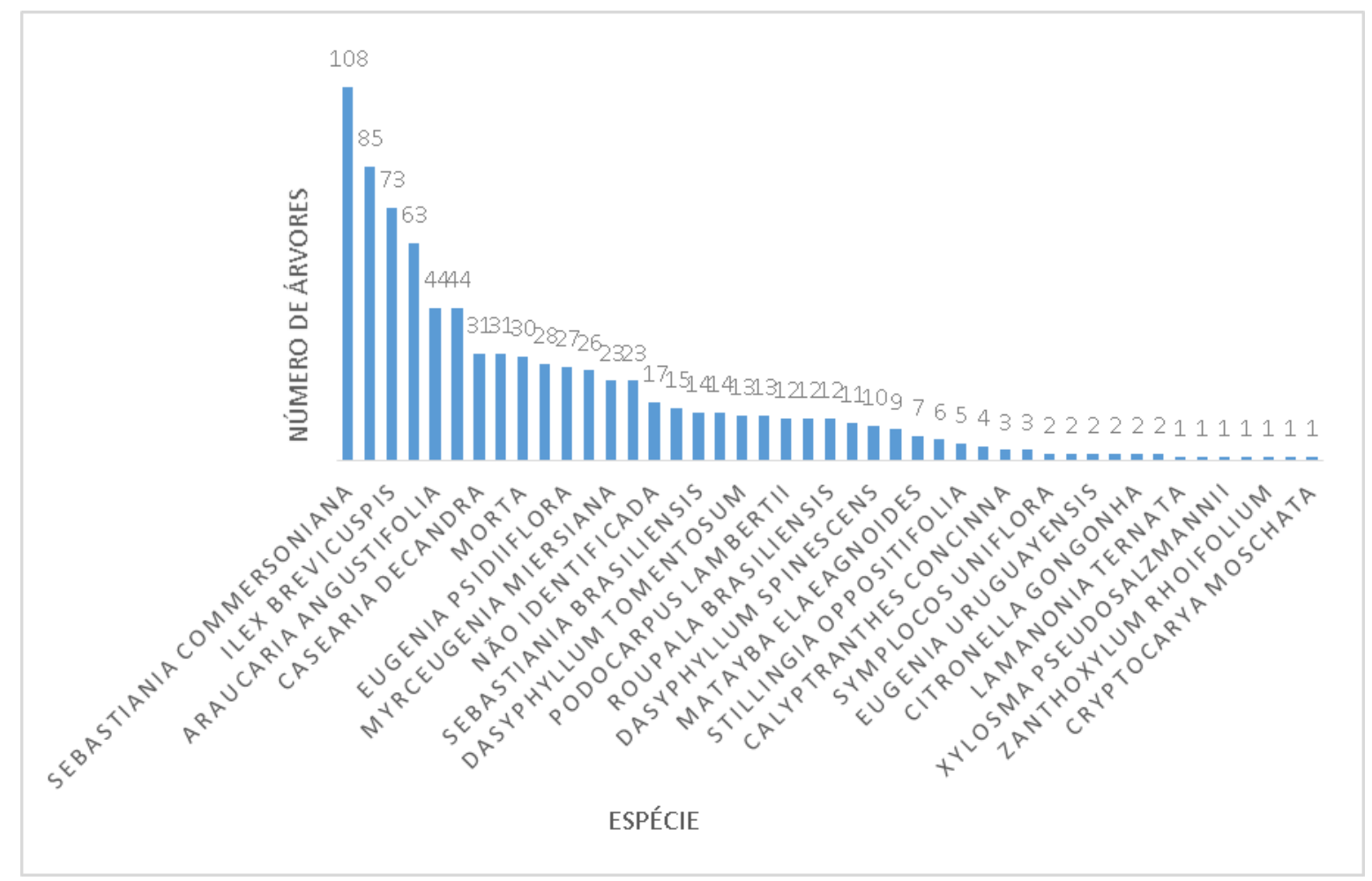

Figura 3. Número de indivíduos amostrados por espécie na Flona-SFP

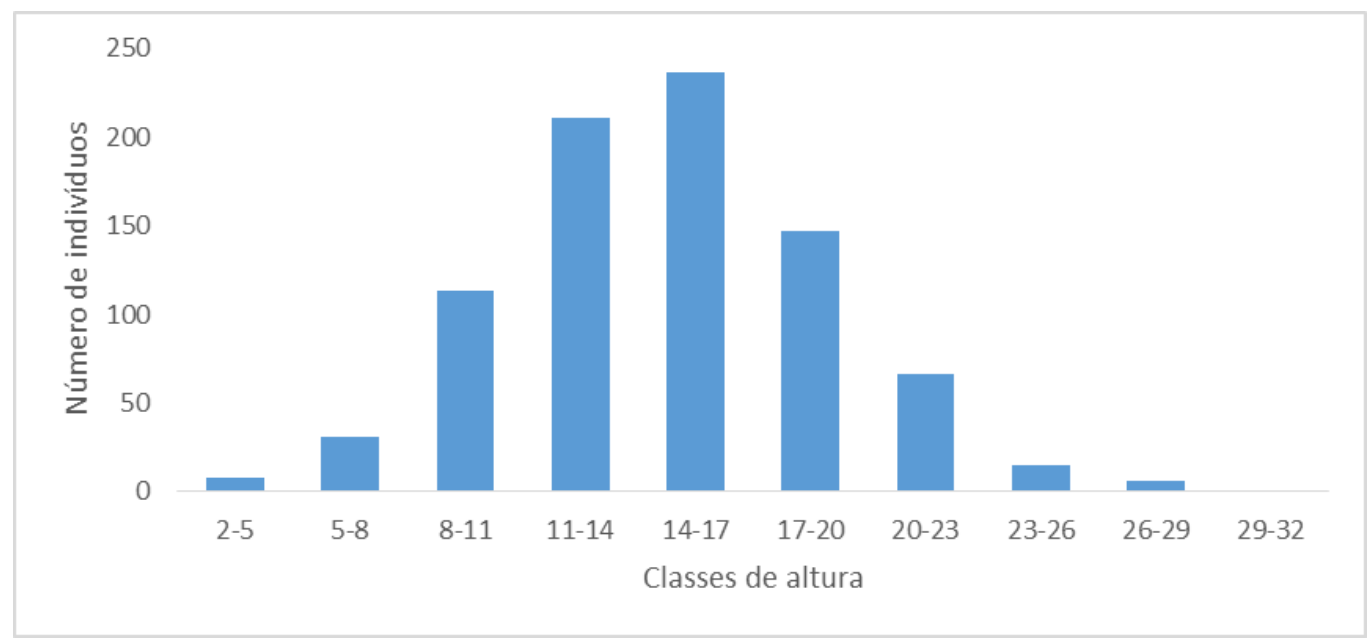

Figura 4. Distribuição do número de indivíduos por classe de altura na Flona-SFP

A família de maior riqueza florística foi a Myrtaceae com 14 espécies, seguida das famílias Lauraceae com 5, Euphorbiacea e Salicaceae com 4 espécies cada uma (Figura 2). Estas famílias juntas foram responsáveis por 64,28\% das espécies catalogadas.

Analisando a distribuição por classes de altura das espécies constatadas, pode-se verificar que a maior parte dos indivíduos posicionou-se nas classes de altura mais centrais, entre 11 e $17 \mathrm{~m}$, sendo o dossel caracterizado principalmente pelas espécies Nectandra megapotamica, Blepharocalyx salicifolius, Citronella gongonha e Araucaria angustifólia.
Nos $10.000 \mathrm{~m}^{2}$ estudados foram encontrados 835 indivíduos pertencentes a 17 famílias, 29 gêneros e 42 espécies (Tabela 1). Resultados semelhantes foram encontrados por Nascimento et al. (2001), numa floresta ombrófila mista, onde verificaram 54 espécies distribuídas em 23 famílias botânicas.

O presente trabalho apresentou densidade absoluta de 835 indivíduos por hectare (Tabela 2). Resultado semelhante foi constatado por Silva et al. (2011) na Flona de São Francisco de Paula, verificado 820 indivíduos por hectare. 
Tabela 1. Relação de famílias e espécies registradas na Flona-SFP

\begin{tabular}{|c|c|}
\hline Família/espécies & Nomes populares \\
\hline \multicolumn{2}{|l|}{ Euphorbiaceae } \\
\hline Sebastiania commersoniana (Baill.) L.B. Sm. \& Downs & Branquilho-comum \\
\hline Sapium glandulatum (L.) Morong & Pau-leiteiro \\
\hline Sebastiania brasiliensis Spreng & Branquilho-leiteiro \\
\hline Stillingia oppositifolia Baill. ex Müll.Arg & Leiterinho \\
\hline \multicolumn{2}{|l|}{ Myrtaceae } \\
\hline Blepharocalyx salicifolius (Kunth) O.Berg & Murta \\
\hline Campomanesia xanthocarpa O.Berg & Guabiroba \\
\hline Eugenia psidiiflora DC & Guamirim \\
\hline Campomanesia rhombea O.Berg & Guabiroba-miúda \\
\hline Myrceugenia miersiana (Gardner) D. Legrand \& Kausel & Guamirim-piloso \\
\hline Myrceugenia cucullata D. Legrand & Guamirim-quebradiço \\
\hline Myrciaria delicatula (DC.) O. Berg & Camboim \\
\hline Eugenia involucrata $\mathrm{DC}$ & Cerejeira-do-mato \\
\hline Myrcia oligantha $\mathrm{O}$. Berg & Guamirim \\
\hline Myrcianthes gigantea (D. Legrand) D. Legrand & Araçá-do-mato \\
\hline Myrcia bombycina DC & Guamirim-do-campo \\
\hline Calyptranthes concinna DC & Guamirim-ferro \\
\hline Eugenia uruguayensis Cambess & Batinga-vermelha \\
\hline Myrciaria tenella (DC.) O. Berg & Camboinzinho \\
\hline \multicolumn{2}{|l|}{ Aquifoliaceae } \\
\hline Ilex brevicuspis Reissek & Caúna-da-serra \\
\hline Ilex paraguariensis A. St. Hil & Erva-mate \\
\hline \multicolumn{2}{|l|}{ Araucareaceae } \\
\hline Araucaria angustifolia & Pinheiro-brasileiro \\
\hline \multicolumn{2}{|l|}{ Lauraceae } \\
\hline Cryptocarya aschersoniana $\mathrm{Mez}$ & Canela-fogo (vicki) \\
\hline Ocotea pulchella (Nees) Mez & Canela-lageana \\
\hline Nectandra megapotamica (Spreng.) Mez & Canela-preta \\
\hline Ocotea lancifolia (Shott.) Mez & Canela pilosa \\
\hline Cryptocarya moschata Nees \& Mart. ex Nees & Canela-cega \\
\hline \multicolumn{2}{|l|}{ Salicaceae } \\
\hline Casearia decandra Jacq. & Guaçatunga \\
\hline Xylosma tweedianum (Clos) Eichler & Sucará \\
\hline Banara parviflora (A. Gray) Benth & Guaçatunga-preta \\
\hline Xylosma pseudosalzmannii Sleumer & Espinho-judeu \\
\hline \multicolumn{2}{|l|}{ Asteraceae } \\
\hline Dasyphyllum tomentosum (Spreng.) Cabrera & Açucará-piloso \\
\hline Dasyphyllum spinescens (Less.) Cabrera & Açucará \\
\hline \multicolumn{2}{|l|}{ Podocarpeaceae } \\
\hline Podocarpus lambertii Klotzsch ex Endl. & Pinheiro-bravo \\
\hline \multicolumn{2}{|l|}{ Proteaceae } \\
\hline Roupala brasiliensis Klotzsch & Carvalho-brasileiro \\
\hline \multicolumn{2}{|l|}{ Sapindaceae } \\
\hline Matayba elaeagnoides Radlk & Camboatá-branco \\
\hline \multicolumn{2}{|l|}{ Syplocaceae } \\
\hline Symplocos uniflora (Pohl) Benth. & Sete-sangrias \\
\hline \multicolumn{2}{|l|}{ Rhamnaceae } \\
\hline Scutia buxifolia Reissek & Coronilha \\
\hline \multicolumn{2}{|l|}{ Cardiopteridaceae } \\
\hline Citronella gongonha (Mart.) R.A.Howard & Gongonha-espinhosa \\
\hline \multicolumn{2}{|l|}{ Rosaceae } \\
\hline Prunus myrtifolia (L.) Hurb. & Pessegueiro-do-mato \\
\hline \multicolumn{2}{|l|}{ Cunoniaceae } \\
\hline Lamanonia ternata Vell. & Guaperê \\
\hline \multicolumn{2}{|l|}{ Dicksoniaceae } \\
\hline Dicksonia sellowiana Hook. & Xaxim \\
\hline \multicolumn{2}{|l|}{ Rutaceae } \\
\hline Zanthoxylum rhoifolium Lam. & Mamica-de-cadela \\
\hline
\end{tabular}


Tabela 2. Parâmetros estruturais da vegetação da Flona-SFP

\begin{tabular}{|c|c|c|c|c|c|c|c|c|c|c|c|c|}
\hline Nome Científico & Nome Popular & $\mathbf{N}$ & $\mathbf{G}$ & DA & DR & FA & FR & DoA & DoR & IVC & IVI & IVIA \\
\hline Blepharocalyx salicifolius & Murta & 85 & 11,255 & 85 & 10,18 & 51 & 8,89 & 11,26 & 23,51 & 33,69 & 42,58 & 51,67 \\
\hline Nectandra megapotamica & Canela-preta & 108 & 5,234 & 108 & 12,93 & 53 & 9,23 & 5,23 & 10,93 & 23,87 & 33,10 & 48,37 \\
\hline Dicksonia sellowiana & Xaxim & 73 & 5,001 & 73 & 8,74 & 36 & 6,27 & 5,00 & 10,45 & 19,19 & 25,46 & 33,75 \\
\hline Citronella gongonha & Gongonha-espinhosa & 44 & 6,363 & 44 & 5,27 & 30 & 5,23 & 6,36 & 13,29 & 18,56 & 23,79 & 28,57 \\
\hline Araucaria angustifolia & Pinheiro-brasileiro & 44 & 3,848 & 44 & 5,27 & 32 & 5,57 & 3,85 & 8,04 & 13,31 & 18,88 & 24,03 \\
\hline Myrciaria delicatula & Camboim & 63 & 1,103 & 63 & 7,54 & 41 & 7,14 & 1,10 & 2,30 & 9,85 & 16,99 & 23,29 \\
\hline Myrceugenia miersiana & Guamirim-piloso & 31 & 1,460 & 31 & 3,71 & 27 & 4,70 & 1,46 & 3,05 & 6,76 & 11,47 & 15,52 \\
\hline Sapium glandulatum & Pau-leiteiro & 30 & 1,196 & 30 & 3,59 & 26 & 4,53 & 1,20 & 2,50 & 6,09 & 10,62 & 12,55 \\
\hline Casearia decandra & Guaçatunga & 31 & 0,565 & 31 & 3,71 & 26 & 4,53 & 0,56 & 1,18 & 4,89 & 9,42 & 14,08 \\
\hline $\begin{array}{l}\text { Campomanesia } \\
\text { xanthocarpa }\end{array}$ & Guabiroba & 28 & 0,918 & 28 & 3,35 & 20 & 3,48 & 0,92 & 1,92 & 5,27 & 8,76 & 12,58 \\
\hline Campomanesia rhombea & Guabiroba-miúda & 26 & 0,856 & 26 & 3,11 & 22 & 3,83 & 0,86 & 1,79 & 4,90 & 8,73 & 11,75 \\
\hline Xylosma tweedianum & Sucará & 27 & 0,861 & 27 & 3,23 & 20 & 3,48 & 0,86 & 1,80 & 5,03 & 8,52 & 12,42 \\
\hline Ilex brevicuspis & Caúna-da-serra & 23 & 0,431 & 23 & 2,75 & 18 & 3,14 & 0,43 & 0,90 & 3,66 & 6,79 & 9,70 \\
\hline Cryptocarya moschata & Canela-cega & 13 & 1,286 & 13 & 1,56 & 9 & 1,57 & 1,29 & 2,69 & 4,24 & 5,81 & 7,50 \\
\hline Ilex paraguariensis & Erva-mate & 23 & 0,328 & 23 & 2,75 & 13 & 2,26 & 0,33 & 0,69 & 3,44 & 5,71 & 8,24 \\
\hline Eugenia involucrata & Cerejeira-do-mato & 14 & 0,927 & 14 & 1,68 & 12 & 2,09 & 0,93 & 1,94 & 3,61 & 5,70 & 7,43 \\
\hline Sebastiania brasiliensis & Branquilho-leiteiro & 15 & 0,650 & 15 & 1,80 & 13 & 2,26 & 0,65 & 1,36 & 3,15 & 5,42 & 7,55 \\
\hline Myrceugenia cucullata & Guamirim-quebradiço & 12 & 0,726 & 12 & 1,44 & 12 & 2,09 & 0,73 & 1,52 & 2,95 & 5,05 & 6,34 \\
\hline $\begin{array}{l}\text { Sebastiania } \\
\text { commersoniana }\end{array}$ & Branquilho-comum & 17 & 0,407 & 17 & 2,04 & 11 & 1,92 & 0,41 & 0,85 & 2,89 & 4,80 & 6,51 \\
\hline Não identificada & $\mathrm{NI}$ & 14 & 0,310 & 14 & 1,68 & 13 & 2,26 & 0,31 & 0,65 & 2,32 & 4,59 & 5,70 \\
\hline Dasyphyllum tomentosum & Açucará-piloso & 13 & 0,396 & 13 & 1,56 & 11 & 1,92 & 0,40 & 0,83 & 2,38 & 4,30 & 5,99 \\
\hline Myrcia bombycina & Guamirim-do-campo & 12 & 0,601 & 12 & 1,44 & 6 & 1,05 & 0,60 & 1,25 & 2,69 & 3,74 & 5,64 \\
\hline Stillingia oppositifolia & Leiterinho & 11 & 0,242 & 11 & 1,32 & 10 & 1,74 & 0,24 & 0,51 & 1,82 & 3,57 & 4,45 \\
\hline Myrcianthes gigantea & Araçá-do-mato & 12 & 0,203 & 12 & 1,44 & 9 & 1,57 & 0,20 & 0,42 & 1,86 & 3,43 & 4,96 \\
\hline Eugenia uruguayensis & Batinga-vermelha & 7 & 0,584 & 7 & 0,84 & 7 & 1,22 & 0,58 & 1,22 & 2,06 & 3,28 & 3,90 \\
\hline Scutia buxifolia & Coronilha & 9 & 0,410 & 9 & 1,08 & 7 & 1,22 & 0,41 & 0,86 & 1,93 & 3,15 & 4,58 \\
\hline $\begin{array}{l}\text { Cryptocarya } \\
\text { aschersoniana }\end{array}$ & Canela-fogo (vicki) & 10 & 0,542 & 10 & 1,20 & 4 & 0,70 & 0,54 & 1,13 & 2,33 & 3,03 & 4,49 \\
\hline Ocotea lancifolia & Canela pilosa & 5 & 0,232 & 5 & 0,60 & 4 & 0,70 & 0,23 & 0,49 & 1,08 & 1,78 & 2,33 \\
\hline Matayba elaeagnoides & Camboatá-branco & 6 & 0,078 & 6 & 0,72 & 4 & 0,70 & 0,08 & 0,16 & 0,88 & 1,58 & 2,53 \\
\hline Lamanonia ternata & Guaperê & 4 & 0,057 & 4 & 0,48 & 4 & 0,70 & 0,06 & 0,12 & 0,60 & 1,30 & 1,56 \\
\hline Prunus myrtifolia & Pessegueiro-do-mato & 3 & 0,076 & 3 & 0,36 & 3 & 0,52 & 0,08 & 0,16 & 0,52 & 1,04 & 1,51 \\
\hline Myrcia oligantha & Guamirim & 2 & 0,115 & 2 & 0,24 & 2 & 0,35 & 0,11 & 0,24 & 0,48 & 0,83 & 1,02 \\
\hline Calyptranthes concinna & Guamirim-ferro & 3 & 0,043 & 3 & 0,36 & 2 & 0,35 & 0,04 & 0,09 & 0,45 & 0,80 & 1,27 \\
\hline Cipós & Cipós & 2 & 0,096 & 2 & 0,24 & 2 & 0,35 & 0,10 & 0,20 & 0,44 & 0,79 & 1,10 \\
\hline Ocotea pulchella & Canela-lageana & 2 & 0,147 & 2 & 0,24 & 1 & 0,17 & 0,15 & 0,31 & 0,55 & 0,72 & 1,04 \\
\hline Symplocos uniflora & Sete-sangrias & 2 & 0,025 & 2 & 0,24 & 2 & 0,35 & 0,02 & 0,05 & 0,29 & 0,64 & 0,83 \\
\hline Myrciaria tenella & Camboinzinho & 2 & 0,020 & 2 & 0,24 & 2 & 0,35 & 0,02 & 0,04 & 0,28 & 0,63 & 0,95 \\
\hline Banara parviflora & Guaçatunga-preta & 2 & 0,017 & 2 & 0,24 & 2 & 0,35 & 0,02 & 0,04 & 0,27 & 0,62 & 0,94 \\
\hline Eugenia psidiiflora & Não identificada & 1 & 0,101 & 1 & 0,12 & 1 & 0,17 & 0,10 & 0,21 & 0,33 & 0,50 & 0,66 \\
\hline Zanthoxylum rhoifolium & Mamica-de-cadela & 1 & 0,090 & 1 & 0,12 & 1 & 0,17 & 0,09 & 0,19 & 0,31 & 0,48 & 0,64 \\
\hline Dasyphyllum spinescens & Açucará & 1 & 0,027 & 1 & 0,12 & 1 & 0,17 & 0,03 & 0,06 & 0,18 & 0,35 & 0,39 \\
\hline Roupala brasiliensis & Carvalho-brasileiro & 1 & 0,014 & 1 & 0,12 & 1 & 0,17 & 0,01 & 0,03 & 0,15 & 0,32 & 0,48 \\
\hline $\begin{array}{l}\text { Xylosma } \\
\text { pseudosalzmannii }\end{array}$ & Espinho-judeu & 1 & 0,011 & 1 & 0,12 & 1 & 0,17 & 0,01 & 0,02 & 0,14 & 0,32 & 0,35 \\
\hline Podocarpus lambertii & Pinheiro-bravo & 1 & 0,009 & 1 & 0,12 & 1 & 0,17 & 0,01 & 0,02 & 0,14 & 0,31 & 0,47 \\
\hline Morta & Morta & 1 & 0,008 & 1 & 0,12 & 1 & 0,17 & 0,01 & 0,02 & 0,14 & 0,31 & 0,35 \\
\hline Total & & 835 & 47,868 & 835 & & 574 & & 47,87 & & 200,00 & & 400,00 \\
\hline
\end{tabular}


A espécie com maior índice de valor de importância (IVI) foi a Blepharocalyx salicifolius que apresentou também o maior índice de valor de cobertura (IVC), a maior dominância (DoA) a segunda maior densidade absoluta (DA) e a segunda maior frequência relativa (FR) (Tabela 3). A Nectandra megapotamica apesar de conferir o segundo maior índice de valor de importância, apresentou a maior frequência absoluta e a maior frequência relativa (Tabla 3 ).

Constatou-se que a área basal $(\mathrm{G})$ dos indivíduos catalogados foi de 47, $87 \mathrm{~m}^{2} / \mathrm{ha}$ (Tabela 3). Este resultado foi semelhante ao valor encontrado por Ferreira et al. (2016) que ao estudarem uma floresta ombrófila mista encontraram valor de $44 ; 49 \mathrm{~m}^{2} / \mathrm{ha}$. O valor encontrado para o índice de Shannon ( $\left.\mathrm{H}^{\prime}\right)$ foi de 3,18 nats. Ind. indicando considerável diversidade florística. O índice de Shanon ( $\left.\mathrm{H}^{\prime}\right)$ foi superior aos encontrados por Silva et al. (2011) de 1,34 nats. Ind. e por Neto et al. (2002); 2,76 nats. Ind, porém inferior ao encontrado por Gomes et al. (2008); 3,53 nats. Ind.

$\mathrm{O}$ Índice de equabilidade de Pielou (J) constatado nesse estudo foi de 0,84 indicando alta uniformidade na composição das parcelas. Este resultado está de acordo com Kanieski et al. (2010) que encontraram valores próximos a 0,80 na flona de São Francisco de Paula.

Analisando a distribuição por classes de altura das espécies constatadas, pode-se verificar que a maior parte dos indivíduos posicionou-se nas classes de altura mais centrais, entre 11 e $17 \mathrm{~m}$, sendo o dossel caracterizado principalmente pelas espécies Nectandra megapotamica, Blepharocalyx salicifolius, Citronella gongonha e Araucaria angustifólia.

Em relação às classes de diâmetro, o maior número de indivíduos foi encontrado nas classes entre 9 e $29 \mathrm{~cm}$ (Figura 5), sendo responsável por 75\% das árvores amostradas. O maior diâmetro encontrado foi de 142 $\mathrm{cm}$, pertencente a uma árvore da espécie Blepharocalyx salicifolius e o menor diâmetro em indivíduo da espécie Myrciaria tenella com 9,93 cm.

A distribuição das classes de diâmetro ficou próxima do "J" invertido ou exponencial negativa, onde existe uma predominância dos indivíduos jovens nas primeiras classes diamétricas, ocorrendo um decréscimo à medida em que avança para as últimas classes; fato que sugere um processo de regeneração da floresta e grande potencial de estoque futuro.

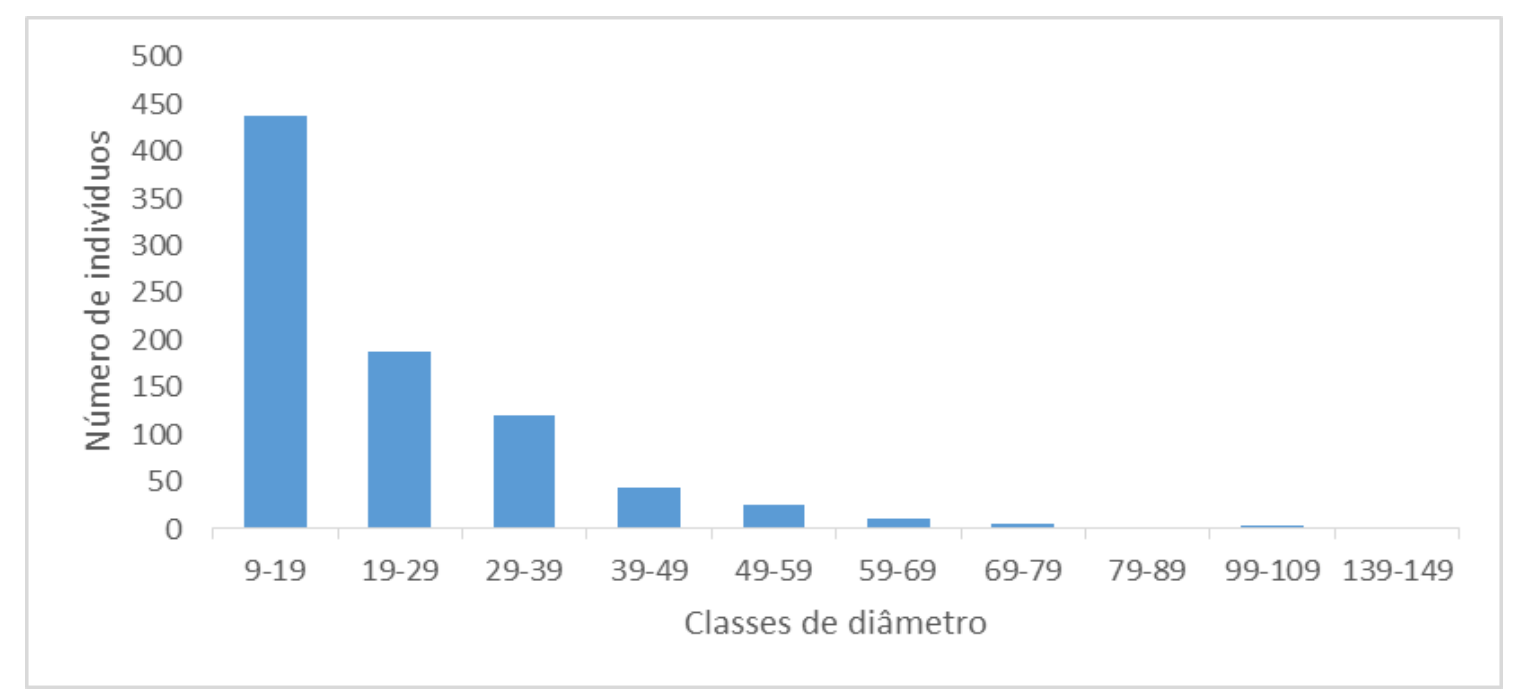

Figura 5. Distribuição do número de indivíduos por classe de diâmetro na Flona-SFP.

\section{Conclusões}

Por meio da análise dos resultados obtidos neste estudo pode-se concluir que a área de estudo apresentou uma boa diversidade florística, comparado com outros estudos realizados para a mesma tipologia florestal.

As famílias Myrtaceae, Lauraceae, Euphorbiacea e Salicaceae foram as que apresentaram maior número de espécies.

As espécies mais abundantes na comunidade estudada foram Sebastiania commersoniana,
Blepharocalyx salicifolius, Ilex brevicuspis, Sapium glandulatum, Araucaria angustifólia e Casearia decandra.

\section{Referências Bibliográficas}

ARAUJO, M. M.; CHAMI, L.; LONGHI, S. J.; AVILA, A. L.; BRENA, D. A. análise de agrupamento em remanescente de Floresta Ombrófila Mista. Ciência Florestal, Santa MariaRS, v. 20, n. 1, p. 1-18, 2010. 
CHAVES, A. D. C. G.; SANTOS, R. M. S.; SANTOS, J. O.; FERNANDES, A. A.; MARACAJÁ, P. B. A importância dos levantamentos florístico e fitossociológico para a conservação e preservação das florestas. Revista ACSA, Campina GrandePB, v. 9, n. 2, p. 42-48, 2013.

DOBROVOLSKI, R.; BOTH, R.; COELHO, I. P.; STOLZ, J. F. B.; SCHÜSSLER, G.; RODRIGUES, G. G.; GUERRA, G.; HARTZ, S. M. Levantamento de áreas prioritárias para a conservação da Floresta Nacional de São Francisco de Paula (RS, Brasil) e seu entorno. Revista Brasileira de Biociências, Porto Alegre-RS, v. 4, n. 1/2, p. 7-14. 2006.

FERREIRA, T. S.; MARCON, A. K.; SALAMI, B.; RECH, C. C. C.; MENDES, A. R.; CARVALHO, A. F.; MISSIO, F. F.; PSCHEIDT, F.; GUIDINI, A. L.; DORNELLES, R. S.; SILVA, A. C.; HIGUCHI, P. Composição florístico-estrutural ao longo de um gradiente de borda em fragmento de Floresta Ombrófila Mista Alto-Montana em Santa Catarina. Ciência Florestal, Santa Maria-RS, v. 26, n. 1, p. 123-134, 2016.

GOMES, J. F.; LONGHI, S. J.; ARAÚJO, M. M; BRENA, A. D. Classificação e crescimento de unidades de vegetação em Floresta Ombrófila Mista, São Francisco de Paula-RS. Ciência Florestal, Santa Maria-RS, v. 18, n. 1, p. 93-107, 2008.

KANIESKI, M. R.; ARAUJO, A. C. B.; LONGHI, S. J. Quantificação da diversidade em Floresta Ombrófila Mista por meio de diferentes Índices Alfa. Scientia Forestalis, Piracicaba-SP, v. 38, n. 88, p. 567-577, 2010.

LEITE, P.F.; $\quad$ KLEIN, $\quad$ R.M. Vegetação. In: IBGE. INSTITUTO BRASILEIRO DE GEOGRAFIA E ESTATÍSTICA. Geografia do Brasil: Região Sul. Rio de Janeiro-RJ: Instituto Brasileiro de Geografia e Estatística, v. 2, 1990. p. 113-150.

LONGHI, S. J.; ARAUJO, M. M.; KELLING, M. B.; HOPPE, J. M.; MÜLlER, I.; BORSOI, G. A.; Aspectos fitossociológicos de fragmento de Floresta Estacional Decidual, Santa Maria, RS. Ciência Florestal, Santa MariaRS, v. 10, n. 2, p. 59-74. 2000.
MARTINS, F. R. Fitossociologia de florestas no Brasil: um histórico bibliográfico. Pesquisa, série Botânica, São Leopoldo-RS, v. 40, n. 1, p. 103-164, 1989.

MUELLER-DOMBOIS, D.; ELLENBERG, H. Aims and methods in vegetation ecology. New York-USA: John Wiley e Sons, 1974. 547p

NASCIMENTO, A. R. T.; SOLON JONAS LONGHI, S.J.; BRENA, D. A. Estrutura e padrões de distribuição espacial de espécies arbóreas em uma amostra de Floresta Ombrófila Mista em Nova Prata, RS. Ciência Florestal, Santa Maria-RS, v.11, n.1, p.105-119. 2001.

NETO, R. M. R.; WATZLAWICK, L. F.; CALDEIRA M. V. W. SCHOENINGER, E. R. Análise florística e estrutura de um fragmento de Floresta Ombrófila Mista Montana, Situado em Criúva, RS, Brasil. Ciência Florestal, Santa Maria-RS, v. 12, n. 1, p. 29-37, 2002.

R CORE TEAM. R: A language and environment for statistical computing. $\mathrm{R}$ Foundation for Statistical Computing, Vienna, Austria: $\mathrm{R}$ foundation for Statistical Computing, 2016. Disponível em: <https://www.Rproject.org/>. Acesso em 22 de jun. de 2016.

SILVA, M. M.; GANADE, G. M. S.; BACKES, A. Fitossociologia do estrato arbóreo de um remanescente de floresta ombrófila mista, na Floresta Nacional de São Francisco de Paula, Rio Grande do Sul, Brasil. Pesquisas, Série Botânica, São Leopoldo-RS, v. 62, n. 1, p. 199-210, 2011.

VILELA, E. A., OLIVEIRA FILHO, A.T.; GAVINALES, M. L.; CARVALHO, D. A. Espécies de matas ciliares com potencial para estudos de revegetação no alto Rio Grande, Sul de Minas. Revista Árvore, Viçosa-MG, v. 17 n. 2, p. $117-$ 128, 1993. 